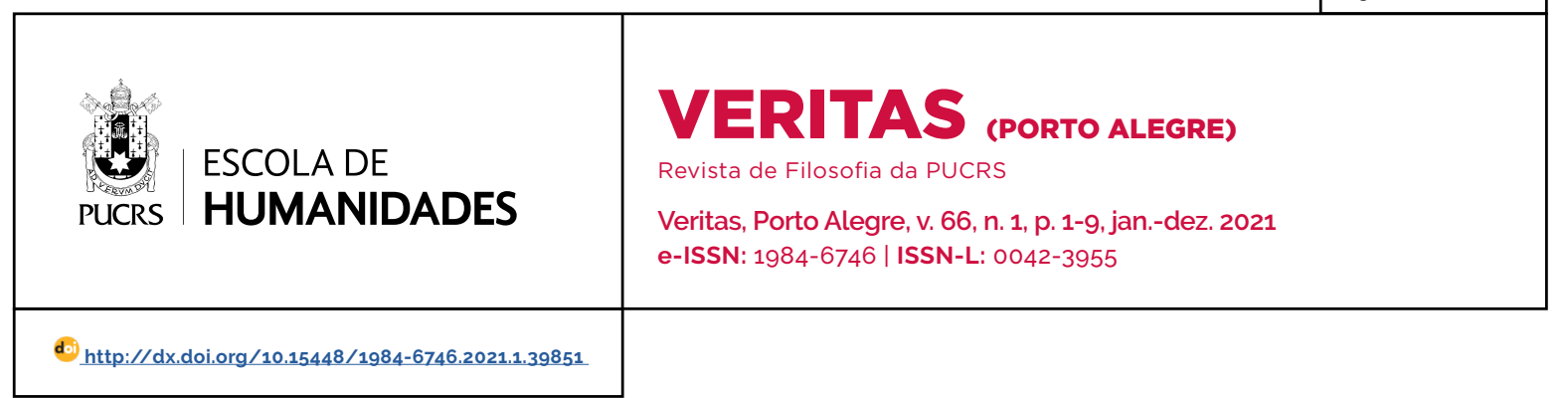

SEÇÃO: TRADUÇÃO

\title{
Ficção e metafísica ${ }^{1}$
}

Fiction and metaphysics

Ficción y metafísica

\section{Peter van Inwagen Tradução de \\ Italo Lins Lemos ${ }^{2}$ \\ orcid.org/0000-0003-2402-9820 \\ italolinslemos@hotmail.com}

Recebido em: 8 jan. 2021. Aprovado em: 17 ago. 2021. Publicado em: 27 dez. 2021.
Muitas obras de ficção tratam diretamente de questões metafísicas. Pode-se pensar nas estórias ${ }^{3}$ [stories] de Olaf Stapledon, Charles Williams ou Jorge Luis Borges. Outras ficções são mais sutilmente e indiretamente relacionadas à metafísica - A la recherche du temps perdu, por exemplo, ou, de um modo bastante diferente, algumas ficções científicas. As relações que várias novelas e estórias mantêm com as questões da metafísica seria um tópico interessante, mas esse não é o tópico do presente artigo, que não é a relevância dessa ou daquela obra para a metafísica, mas sim da própria existência de tal coisa como a ficção. Veremos como esta reflexão filosófica sobre a ficção pode nos levar a certas conclusões metafísicas notáveis. Não é surpreendente que a área da metafísica a qual essas conclusões pertencem seja a ontologia. A palavra, embora não o estudo que ela representa, é nova - é provavelmente uma cunhagem do século XVII. No presente século, a palavra "ontologia" está associada principalmente aos nomes de Heidegger e Quine. Usarei essa palavra no sentido de Quine: como um nome para o estudo que tenta responder à pergunta "o que há?".

As contribuições de Quine para esse estudo são de importância central para a tese deste artigo. Essas contribuições podem ser divididas em duas partes: aquelas que pertencem à própria ontologia e aquelas que pertencem ao que podemos chamar de metaontologia. Por "própria ontologia" de Quine, refiro-me à sua tentativa efetiva de responder à questão "o que há?". Essa tentativa é de grande interesse intrínseco, mas não é relevante para o meu tópico. Por "metaontologia" de Quine, refiro-me à sua famosa discussão sobre o que significa perguntar por

\section{(c) (i)}

Artigo está licenciado sob forma de uma licença Creative Commons Atribuição 4.0 Internacional.

\footnotetext{
1 INWAGEN, Peter van. Fiction and Metaphysics. Philosophy and Literature, Baltimore, v. 7. n. 1, p. 67-77, 1983. C 1983 Johns Hopkins University Press. Reprinted with permission of Johns Hopkins University Press.

2 Universidade Estadual de Maringá (UEM), Maringá, Paraná, Brasil.

3 Inwagen usa o termo "estória" [story] para falar sobre narrativas ficcionais e "história" [history] para falar sobre narrativas factuais. Embora o uso do termo 'estória' não seja comum em lingua portuguesa, decidi empregá-lo para captar essa distinção (N.T.).
} 
o que há e a suas famosas teses sobre como abordar essa questão. ${ }^{3}$ Essas teses são o produto de um esforço realmente notável de se pensar claramente sobre questões que quase ninguém havia pensado com clareza, e uma apreciação adequada delas nos libertará de algumas ilusões muito antigas e muito fortes acerca do ser e da existência. Ou assim diriam muitos filósofos, incluindo o presente autor. E, ainda assim, a metaontologia de Quine, quando é combinada com o que parecem ser fatos muito simples e óbvios sobre a ficção, produz um resultado que parece ser apenas obviamente errado: que nomes retirados das obras de ficção ("Sr. Pickwick" e "Tom Sawyer", por exemplo, assim como nomes próprios de outros tipos, como "Dotheboys Hall" e "Barchester") denotam objetos existentes. A tese deste artigo é que essa consequência da metaontologia de Quine não constitui uma reductio ad absurdum; ao invés disso, a metaontologia de Quine deveria ser conservada e, essa consequência, aceita.

Examinarei primeiro a metaontologia de Quine em uma acepção geral e, em seguida, na sua aplicação à ficção. Em uma acepção geral, a meta-ontologia de Quine pode ser vista como abrangendo quatro proposições:

(1) Ser é o mesmo que existência. Isso é, dizer que coisas de certo tipo existem e dizer que há coisas daquele tipo é dizer, basicamente, a mesma coisa. Por exemplo, dizer que cavalos existem é dizer que há cavalos, e dizer que houve tal pessoa como Homero é dizer que Homero existiu. Isso pode parecer óbvio, mas, sob reflexão, pode parecer menos óbvio. Suponha que eu esteja discutindo sobre as alucinações de alguém e diga: "há várias coisas em que ele acredita, mas elas não existem". A principio, parece que estou dizendo que há coisas - o veneno em sua bebida, a malícia do seu tio, e assim por diante - que não existem. Tomando um exemplo um tanto mais metafísico, suponha que eu tenha lido uma carta para o editor de um jornal, e que o autor dela argumente que a contracepção seja um pecado, uma vez que ela evita que existam pessoas que poderiam existir na ausência de métodos contraceptivos. Esse pode ser um argumento ruim por vários motivos que não têm a ver com metafísica, mas está certamente claro que seu proponente acredita que há pessoas não concebidas, pessoas que poderiam ter existido, mas que, por causa de certos atos de contracepção, não existem. Talvez alguém que reflita sobre esses exemplos concluirá que não é óbvio que ser seja o mesmo que existir. Mas seja ou não óbvio, isso é verdade. Não há veneno não existente na bebida do paranoico. Não há pessoas não concebidas. Em suma, não há coisas que não existem. Não posso defender essa tese na profundidade que as questões que ela suscita merecem. Direi apenas o seguinte: se você pensa que há coisas que não existem, dê-me o exemplo de uma. A resposta correta ao seu exemplo será "isso também existe" ou "não há tal coisa como essa";

(2) Ser é univoco. ( $E$, dado que existência é o mesmo que ser, existência é univoca). Muitos filósofos pensaram que "há" e "existe" significavam uma coisa quando eram aplicados a objetos materiais e outra quando aplicados, digamos, a mentes; e ainda outra coisa quando aplicados a (ou retidos de) seres sobrenaturais; e novamente mais outra coisa quando aplicados a abstrações, como números ou possibilidades. Essa é, evidentemente, uma posição extremamente atraente. Os estudantes de graduação aderem facilmente a essa posição, e é muito dificil convencer qualquer um que a aceita de que ela seja falsa, ou até mesmo que ela não seja obviamente verdadeira. Mas ela é falsa. Talvez a consideração a seguir mostrará o porquê de ela ao menos não ser obviamente verdadeira. Ninguém estaria inclinado a supor que numerais como "seis" ou "quarenta e três" signifiquem coisas diferentes quando são usados para contar tipos diferentes de objetos. A própria essência da aplicabilidade da aritmética é que números possam contar qualquer coisa: se você escreveu treze épicos e eu tenho treze gatos, então o número dos seus épicos é o número dos meus gatos. Mas existência está intimamente ligada ao número. Dizer que unicórnios não existem é dizer algo muito parecido a que o número de unicórnios é zero; dizer que cavalos existem é dizer que o número de cavalos é um ou mais. E dizer que anjos, ou ideias, ou números primos existem é dizer que o número de anjos, ou ideias, ou números primos, é maior que zero. A univocidade do número e a conexão íntima entre enumeração e existência deveriam nos convencer de que há ao menos uma razão muito boa para se pensar que a existência seja univoca. (A noção de que o significado de "existe" deve ter algo a ver com espaço e matéria quando "existe" é aplicado a mesas e cadeiras, e que essa palavra deve ter algum outro significado quando é aplicada, digamos, a objetos matemáticos como campos e mapas. é uma das antigas e fortes ilusões metafísicas das quais os escritos de Quine sobre a existência deveriam ter nos libertado);

(3) O terceiro componente da metaontologia de Quine é difícil de expor, mesmo que de modo

\footnotetext{
4 As concepções metaontológicas de Quine estão dispersas no decorrer de seus escritos. Uma famosa exposição sistemática delas pode ser encontrada em "Sobre o que há", em De um Ponto de Vista Lógico. Mas este artigo está longe de ser uma exposição completa da meta-ontologia de Quine.
} 
impreciso, sem alguma discussão de lógica formal. Há, na lógica padrão contemporânea, a lógica que temos de Frege e Russell, um símbolo chamado de quantificador existencial, que é comumente escrito como um E maiúsculo invertido em fonte sans-serif e pronunciado como "existe a", ou "há a" ou "para algum". Assim, " $\exists x \times$ é um cachorro" é lido como "há um x tal que x é um cachorro" ou "para algum $x, x$ é um cachorro". Esse simbolo pertence a uma familia de simbolos sistematicamente inter-relacionados que formam coletivamente um instrumento de grande beleza e utilidade para representar a estrutura lógica das declarações e para examinar as relações lógicas entre as declarações. (Russell disse uma vez que uma boa notação é como um professor vivo; ele estava pensando nesse sistema de simbolos). A terceira tese de Quine é que esse simbolo, o quantificador existencial, representa adequadamente aquele sentido singular de ser ou existência que figura em nossas asserções cotidianas ou científicas; que esse símbolo e as regras para usá-lo são melhor compreendidas como uma arregimentação dos "existe" e "há" cotidianos. (O próprio nome quantificador existencial sugere que Quine esteja certo quanto a isso; em razão disso, os filósofos que rejeitam a terceira tese às vezes preferem chamar esse simbolo de quantificador particular);

(4) Eu disse que para Quine a ontologia é o estudo que tenta responder a questão "o que há?". O quarto componente da metaontologia de Quine nos dá um modo geral de abordar essa questão. Da forma como Quine encara o assunto, o problema de decidir em quê acreditar sobre aquilo que há é um caso especial muito direto do problema de decidir em quê acreditar - ou, de maneira mais abrangente, um caso especial do problema de decidir quais teorias aceitar. Para descobrir o que há, descubra quais teorias aceitar. Para descobrir como descobrir o que há, descubra como descobrir quais teorias aceitar. (Tarefas nada fáceis, com certeza, mas às quais estamos atados caso tenhamos quaisquer interesses científicos ou epistemológicos).

Suponhamos que eu tenha de algum modo descoberto quais teorias aceitar, e suponhamos que, como resultado, eu aceite, digamos, a Teoria Geral da Relatividade, a Cromodinâmica Quântica, a concepção Verstehen das ciências sociais, a tese Chomskiana da gramática inata, e o dogma da Presença Real. (Como os itens dessa lista mostram, estamos usando "teoria" em um sentido amplo: uma teoria pode ser muito simples ou muito complexa, e dizer que alguém aceita certa teoria não implica que alguém esteja de algum modo incerto quanto à verdade de suas proposições constituintes). Agora que sei quais teorias aceito, estou apto a responder à questão "o que há?". (Ou, ao menos, estou apto a encontrar uma resposta tão boa quanto aquela que um ser com meus recursos finitos e imperfeitos pode encontrar. Devido a minha finitude e imperfeições, haverá aspectos do mundo que não podem ser representados ou que são representados de modo equivocado em minhas teorias e, como consequência, haverá mais coisas entre o céu e a Terra do que é sonhado em minha filosofia, e mais coisas sonhadas em minha filosofia do que há no céu e na Terra. Isso, infelizmente, parece ser inevitável).

Para descobrir o que há, uma vez que descobri quais teorias aceitar, não preciso mais do que encontrar o que as minhas teorias dizem que há. Às vezes isso é fácil. A teoria chamada teísmo, por exemplo, diz que - na verdade, consiste na asserção de que - há um Deus. Mas amiúde as coisas não são tão simples, pois uma teoria pode, em certo sentido, dizer de algo que ele existe, sem vir à tona e dizê-lo. Por exemplo, normalmente não se pensaria que a mecânica clássica assira a existência de números, e ainda assim as asserções típicas da mecânica são asserções sobre as relações entre conjuntos de números. Eu deveria, portanto, apenas em virtude da aceitação da descrição clássica dos movimentos das coisas físicas em resposta às forças imprimidas, também aceitar a existência de certas coisas não-físicas, a saber, os números que mesuram os movimentos e as forças? Essa é uma pergunta traiçoeira à qual a meta-ontologia de Quine fornece uma resposta: o que devo fazer, no caso geral, é traduzir minhas teorias em um simbolismo da lógica formal moderna (aquele sistema de símbolos flexivel e poderoso que inclui “ $\exists$ ”). Então devo examinar as sentenças das minhas teorias e ver quais delas começam com um quantificador existencial, e essas sentenças me dirão o que há. Por exemplo, se a mecânica gravitacional clássica contém a sentença que começa “ $\exists x$ é um número e...», então, ao aceitar essa teoria, eu me comprometo a aceitar a existência de ao menos um número.

Por quê? Bem, aceitar uma teoria é aceitá-la como verdadeira. E se uma teoria contém uma 
sentença que começa com " $\exists$ x é um número e...", então essa teoria é verdadeira somente se houver ao menos um número. Agora pode ser que alguém queira aceitar, digamos, a mecânica clássica, e também queira ser um nominalista. Esse individuo pode protestar dizendo que, ao aceitar a mecânica clássica, ele não defende realmente a existência dos números. Ele pode fazer um discurso como esse: "concedo que quando faço uso da mecânica clássica, às vezes pareço estar dizendo que há números de tal descrição. Mas essa é apenas uma maneira de falar que acho conveniente. Eu não abraço mais a ontologia platônica ao empregar essa maneira conveniente de falar do que a astronomia ptolomaica ao empregar a linguagem conveniente do nascer e do pôr do sol". Não há algo de errado com essa fala, na concepção de Quine. Mas ele insistirá que o autor da fala nos mostre como - ao menos em princípio - eliminar da sua teoria aquelas sentenças que asserem a existência de números. Se ele se recusa a fazê-lo, ele está tratando um princípio filosófico da mesma maneira que alguém que afirma ser ateu, mas que explica a existência do mundo dizendo que Deus o criou e que soluciona essa contradição aparente ao dizer que sua referência a Deus é "apenas uma maneira de dizer" e se recusa a dizer outra palavra sobre o assunto. A tese de Quine que a ontologia de uma teoria formal é revelada por suas sentenças constituintes que começam com um quantificador existencial é frequentemente chamada de seu "critério de comprometimento ontológico". Mas esse critério não revelará os comprometimentos ontológicos do individuo que aceita a teoria, a menos que ele a aceite como literalmente verdadeira, assim como os comprometimentos de um individuo a respeito dos movimentos da Terra e do sol serão revelados apenas pela análise das suas declarações sobre a Terra e o sol que ele considera literalmente corretas.

Finalizamos a análise generalista da metaontologia de Quine. Retornemos ao assunto da ficção. O que se pode dizer sobre a ontologia da ficção se se aceita a metaontologia de Quine? O percurso parece ser claro: deve-se decidir primeiro quais teorias sobre a ficção aceitar, e então deve-se traduzir essas teorias em uma linguagem da lógica formal e ver o que elas têm a dizer sobre o que há.

O que são teorias sobre ficção?

Permita-me recuar momentaneamente nessa questão e inventar uma tribo de primatas, assim como os filósofos fazem quando estão desalentados pela complexidade do mundo real.

Suponha que haja uma tribo cujos membros amam estórias sobre feitos heroicos. Os membros dessa tribo têm uma palavra para estórias e as classificam em três tipos: histórias [histories], mentiras e ficções. As "ficções", diferentemente das histórias e como as mentiras, são produtos da imaginação; diferentemente das mentiras, no entanto, elas não têm o intuito de enganar, pois, quando alguém conta uma ficção, sua plateia sabe que o que está sendo contado a ela não é uma história, e ele sabe que ela sabe, e ela sabe que ele sabe que ela sabe, e assim por diante. Poderiamos, se tivéssemos tempo, imaginar um estágio mais primitivo no desenvolvimento da nossa tribo, quando todas as suas estórias eram ou histórias (talvez contendo uma borrifada de erros honestos) ou mentiras. Poderiamos especular acerca dos modos pelos quais a prática institucional de contar ficções pode ter se desenvolvido a partir da prática institucional de recitar histórias padronizadas (talvez embelezando-as um pouco ao contá-las novamente) e da prática contrainstitucional de contar mentiras (ocasionalmente exposta depois de ter ganho grande popularidade sob a forma de histórias). É discutivel se haveria qualquer verdade em nossas especulações; ou ao menos é discutível se haveria qualquer verdade nelas para além do tipo mítico de verdade que algumas pessoas encontram na estória do Contrato Social. O ato de contar narrativas ficcionais quase certamente não é um desenvolvimento cultural. É muito mais provável que a ficção seja parte de nossa biologia, como a linguagem e a habilidade de reconhecer faces humanas. Não obstante, não temos tempo para essa questão. De qualquer forma que a prática tenha sido originada, os membros da nossa tribo contam ficções. 
Se eles contam ficções, então, por serem membros de nossa espécie conversadora, eles provavelmente falam sobre ficções. Que tipos de coisas eles podem dizer? Quão profundamente suas conversas sobre ficções podem penetrar suas ficções? Podemos distinguir dois "graus de envolvimento ficcional". Aqui estão alguns exemplos de uma sentença de cada grau.

\section{Grau um}

"Aquela estória que ouvimos na noite passada foi dificil de entender"

"Sua estória nova foi ainda mais entediante que a dela".

"Há algumas estórias que eu gostaria que nunca acabassem".

"Eu dormi durante a estória".

"Sua estória me lembra a dela".

\section{Grau dois}

"Aquela estória que ouvimos na noite passada tinha um enredo intricado".

"Seu herói era ainda mais entediante que o dela".

"Quando ouço certas estórias, parece que sou envolvido pela ação".

"Dormi durante a estória - como ela acabou?".

"Ele tomou emprestado o seu artifício de ter um personagem em uma estória, que conta uma estória".

Podemos dizer que o grau um abrange contações holísticas de estórias, enquanto o grau dois abrange contações analiticas. O primeiro trata cada estória como um todo desestruturado, e o segundo como coisas que podem ser desmembradas e tomadas à parte in intellectu. Uma diferença importante entre esses dois graus - mas não é a diferença definitiva - é que o que é dito no primeiro grau é aplicável às histórias (e ipso facto às mentiras, que se representam como histórias), ao passo que o que é dito no segundo grau é aplicável apenas à ficção. (Como a maioria das generalizações, essa precisa ser qualificada. Nós somos tão sofisticados, nós, pessoas pós-neolíticas, que somos difíceis de ser generalizados. Mas quando dizemos do livro de memórias de Field Marshal Montgomery que não é difícil dizer quem é o herói da sua estória, ou afirmar das Guerras das Rosas que seu enredo era muito complicado, estamos dizendo algo imensamente sofisticado).

Voltemos a nossa atenção ao segundo grau do envolvimento ficcional, à contação analítica de estória. A contação analítica de estória, se for altamente teórica, aplicada a textos padrão, informada pelo conhecimento de uma tradição literária, e séria em sua intenção, ela será chamada de crítica. (Mas, é claro, nem todas as críticas são contação analítica de estória, uma vez que há produções literárias - poemas líricos, por exemplo - que não são estórias). Será conveniente, no entanto, chamar de crítica toda contação analítica de estória. Portanto, o que chamaremos de crítica existe até mesmo entre os membros da minha tribo primitiva, e qualquer criança ou cultura que for capaz de falar de enredos e personagens é capaz de fazer críticas

Ainda há pouco recuei da pergunta "o que são teorias sobre ficção?". Agora estou apto a respondê-la: teorias sobre ficção são teorias críticas no sentido presente do termo: teorias que tratam estórias como possuindo uma estrutura interna. Mas teorias criticas, quando ouvidas do modo como Quine nos ensinou a ouvir teorias, contam-nos algo de grande interesse metafísico: que há objetos ficcionais - coisas como Sr. Pickwick. É evidente que as próprias estórias não nos contam quaisquer dessas coisas. Se os membros de certa tribo contaram ficções, mas nunca conversaram sobre ficções, ou se eles conversaram sobre ficções, mas permaneceram no primeiro grau de envolvimento ficcional, eles nunca diriam ou fariam qualquer coisa que os comprometessem à tese de que há objetos ficcionais. Contrariamente a o que G. E. disse em um simpósio famoso, quando Dickens escreveu "Sra. Bardell desmaiou nos braços do Sr. Pickwick", ele não estava dizendo algo sobre alguém chamado "Sra. Bardell" ou sobre alguém 
chamado "Sr. Pickwick".4 Ele não estava dizendo algo sobre eles porque ele estava dizendo nada sobre nada. O que ele fez foi construir um objeto linguístico que seus leitores poderiam, em certo sentindo, fingir que era um registro dos feitos das pessoas - dentre outras - chamadas "Sra. Bardell" e "Sr. Pickwick". 5

São apenas as teorias críticas que nos contam que há objetos ficcionais, porque são apenas as teorias críticas que contêm sentenças como essas:

"Há personagens em algumas novelas do século XIX que são apresentados com maior riqueza de detalhe físico do que qualquer personagem em qualquer novela do século XVIII".

"Alguns personagens de novela são intimamente modelados a partir de pessoas reais, enquanto outros são inteiramente produtos da imaginação literária, e normalmente é impossivel dizer quais personagens pertencem a cada uma dessas categorias exclusivamente por meio de análise textual".

"Dado que os novelistas ingleses do século XIX foram, em grande medida, ingleses convencionais, podemos esperar que a maioria das novelas desse período contenha italianos ou franceses estereotipados e cômicos; mas muito poucos personagens como esses existem".

Tais sentenças podem ser veículos de verdade objetiva, assim como certamente podem as sentenças mais enfadonhas acerca de pedras, substâncias químicas e números. Portanto, certamente, aqueles entre nós que estão interessados na natureza da ficção desejarão aceitar teorias que contenham essas sentenças - ou se não essas sentenças, então outras que possuam essencialmente as mesmas implicações ontológicas. Mas, essas sentenças, se elas forem traduzidas do modo óbvio na linguagem da lógica formal, produzirão sentenças que começam como $\exists$ “ $\exists x$ é um personagem e...". Portanto, aquele que acredita que o que essas sentenças dizem é literalmente verdadeiro e que aceita o que parecem ser as traduções formais óbvias dessas sentenças, aceita a tese que há personagens ficcionais. Evidentemente, alguém que emprega sentenças como essas pode querer dizer que o seu uso delas é meramente uma maneira de falar e que ele não acredita que personagens ficcionais realmente tenham algum tipo de ser. Mas então estamos dentro dos nossos direitos se perguntarmos a ele como ele reescreveria ou parafrasearia tais sentenças a fim de remover suas implicações enganosas. Se de fato é possivel produzir paráfrases de tais sentenças - isso é, de sentenças que, lidas secundun litteram, dizem que há personagens ficcionais - de tal forma que as paráfrases pareçam intuitivamente "dizer a mesma coisa que" as originais e, ainda assim, sequer parecerem dizer que há personagens ficcionais, é uma questão de filosofia puramente técnica que não podemos tentar discutir aqui. (É, ao menos, muito difícil produzir tais paráfrases).

Ao invés de discutir essa questão, levantemos a questão do porquê de que ninguém deveria querer produzi-las. Por que não simplesmente aceitar a tese de que há objetos ficcionais? (Presumivelmente, qualquer argumento que mostrou que havia personagens poderia mostrar que havia objetos ficcionais além dos personagens: lugares e edificios ficcionais, por exemplo; mas restrinjamos nossa discussão aos personagens). A resposta seria provavelmente algo como isso: "bem, observemos um personagem ficcional particular - digamos, Sra. Gamp. Se houvesse tal pessoa como ela, então as pessoas de Londres na década de 1840 seriam capazes de procurá-la e conversar com ela. Mas não havia qualquer Sra. Gamp para eles procurarem - nem havia qualquer Sr. Pecksniff; nem nunca houve qualquer Pickwick, Anna Karenina ou Tom Sawyer. Em suma, não há personagens ficcionais. Cada um desses personagens, se ele ou ela tivesse qualquer tipo de ser, teria certa localização espaçotemporal e exibiria naquela localização certo conjunto de propriedades, um conjunto que poderia ser extraido de várias passagens descritivas da ficção. Mas é óbvio que se pudéssemos visitar a localização 
que qualquer um desses personagens supostamente deveria ocupar, encontrariamos ninguém com as propriedades requeridas".

Essa é uma dificuldade real. Muitos dos filósofos que acreditam em Sra. Gamp et al. considerarão menos difícil do que alguém que aceita a meta-ontologia de Quine. Alguns filósofos pensam que há coisas que não existem, em uma categoria na qual eles colocariam Sra. Gamp. Eles dirão: "a razão pela qual não poderíamos tê-la encontrado em Londres na década de 1940 é que ela não existe. É claro que não se pode 'encontrar' coisas não existentes". Mas essa resolução da dificuldade não está aberta a aqueles que defendem que existência e ser são idênticos, que há nada que não existe. Outros filósofos dirão: "Sra. Gamp existe, mas ela desfruta um modo de existência, a existência ficcional, que é diferente da sua e da minha. Essa é a razão pela qual ninguém poderia tê-la encontrado". Mas essa resolução da dificuldade não está aberta para aqueles que mantêm que a existência é univoca, que existência não aparece em tipos, classes ou estilos.

É difícil levar a sério a última dessas propostas. Postular "modos" de existência sem explicação é preferir o roubo à labuta honesta. Mas a primeira a proposta de separar o ser da existência - vale a pena ser levada a sério. Essa parece ser a posição a qual alguém é levado quando não consegue responder a objeção que estamos considerando. Várias considerações têm sido alegadas em suporte a ela, mas apenas a ficção, na minha concepção, apresenta-nos um argumento muito bom para acreditar no não-existente. Anteriormente, recomendei um caminho curto com tentativas típicas de dar exemplos de coisas não-existentes. Se alguém sugere, digamos, a montanha de ouro de Meinong como um exemplo de algo não existente, dever-se-ia replicar como se segue: "não há montanha de ouro, portanto, você não pode sugeri-la como um exemplo de nada; ela não está lá para ser sugerida". Mas se alguém sugere Sra. Gamp como um exemplo de uma coisa não existente, não se pode dispensá-la tão facilmente. Eu realmente não posso dispensá-la. Pois, na minha concepção, ela está lá para ser sugerida.

O que posso dizer? A lógica deixa apenas um caminho aberto para mim. Digo que a Sra. Gamp existe (no único sentido que há de "existe"); concedo que em 1843 não havia em Londres uma enfermeira gorda, velha, ébria e que costumava carregar um guarda-chuva, chamada "Sarah Gamp", que tinha uma voz rouca e um olho umedecido, que ela tinha um poder notável de revirar e mostrar apenas a sua parte branca. Portanto, devo concluir que Sra. Gamp tinha, ou tem - os tempos verbais tendem a ficar um pouco embaralhados nas discussões sobre as propriedades de personagens ficcionais ${ }^{6}$ - nenhuma das propriedades dessa lista. Nem, na minha concepção, é estritamente verdadeiro que ela seja humana, feita de carne e osso, ou sequer uma habitante do mundo físico.

Bem, o que ela é então? No jargão filosófico, ela é uma entidade teórica da crítica literária. Seu status ontológico pode ser comparado a aquele de um enredo, um esquema de rimas, uma passagem narrativa, ou um padrão recorrente de imagens. Ela é feita da mesma coisa que eles são feitos.

"Mas, olha. Deve haver algum sentindo em que é verdadeiro que a Sra. Gamp era apreciadora de gim. Se você disser que é falso que ela era apreciadora de gim - presumivelmente porque realmente não podemos dizer que as entidades teóricas da crítica podem beber - como você distinguirá entre o sentido em que é falso que ela era apreciadora de gim e o sentido em que é falso que ela era uma abstêmia? Se é falso que ela era apreciadora de gim, deve haver um sentindo em que é ainda mais falso que ela era uma abstêmia".

Esse ponto está correto, é claro. Receio que devamos simplesmente enfrentá-lo por estipulação. Devo simplesmente introduzir a palavra "sustentar" ["hold"] como um termo de arte e dizer que, apesar de a Sra. Gamp não ter a propriedade de ser apre-

\footnotetext{
6 Há algumas razões interessantes para essa tendência, que não posso aprofundar aqui. Veja Felix Martinez-Bonati, "Representation and Fiction", Dispositio, v. 5. p. 19-33, 1980.
} 
ciadora de gim, ela a sustenta. Ser uma abstêmia, por outro lado, é uma propriedade que ela não tem, nem sustenta. Isso não quer dizer que ela não tenha propriedades. Eu diria que, assim como as outras coisas, para cada propriedade dada, ou ela tem aquela propriedade ou a sua negação. Aqui estão algumas propriedades que ela tem: ser uma entidade teórica da crítica; ser uma vilã satírica; ter sido criada por Dickens; ter sido introduzida no Capítulo 19 de Martin Chuzzlewit; não ser uma mulher; não ser feita de carne e osso; sustentar a propriedade de ser uma mulher.

"Mas o que é essa sustentação?". Não posso defini-la. Posso apenas dar exemplos. Mas todos nós a entendemos bem o suficiente. Há uma relação intima que a vilã satírica principal de Martin Chuzzlewit comporta com a propriedade de ser apreciadora de gim. Há uma intima relação que ela comporta com a propriedade de ser introduzida no Capítulo 19. A última, é claro, é a relação chamada ter na fala cotidiana; a primeira obviamente não é a mesma que a última; escolhi o nome "sustentar" para ela.

Temos chamado a Sra. Gamp de "ela", apesar do fato de ela não ter a propriedade de ser fêmea. Ao fazê-lo, temos seguido uma convenção de acordo com a qual é usual falar sobre personagens ficcionais como se eles tivessem as propriedades que eles sustentam. Essa mesma convenção subscreve nosso uso do "é" da predicação em sentenças como "Sra. Gamp é gorda". Essa convenção é óbvia e natural. Se os autores, ao apresentarem suas estórias ao público, estão em certo sentido fingindo ter produzido histórias, então não é de se surpreender que os críticos devessem fingir ao menos às vezes, naquele sentido, estar discutindo histórias. E, é claro, se se está fingindo discutir uma história, usar-se-á pronomes pessoais e o "é" da predicação.

Essa, em um esboço muito amplo, é a teoria sobre a natureza metafísica dos personagens ficcionais: como todo o resto, eles existem; eles são entidades teóricas da critica, como os enredos, digressões e apartes para o leitor; eles não têm tais propriedades como as que você e eu temos, mas apenas propriedades "literárias" como ser uma vilã ou ser um personagem secundário, apesar de eles comportarem outro tipo de relação (que eu arbitrariamente chamo "sustentar") com tais propriedades como as que você e eu temos. Há muito mais que poderia ser dito para se fornecer uma exposição completa dessa teoria.7 Meu objetivo, no entanto, não foi apresentar uma teoria desenvolvida por completo, mas mostrar como a ficção apresenta um problema para o metafísico e como um metafisico tentou lidar com ele. Permita-me encerrar ao apontar uma vantagem desta teoria.

Considere a famosa pergunta, "quantos filhos teve Lady Macbeth?". Uma linha tradicional de pensamento discorre como a seguir: qualquer resposta definitiva para essa pergunta estaria errada. ("Nenhum" estaria errada, "um" estaria errada, "dois" estaria errada, e assim por diante). Mas, de acordo com as regras da lógica que aplicamos aos seres ordinários e não ficcionais, alguma resposta definitiva deveria estar correta. Portanto, a lógica ordinária não é aplicável à ficção, e uma "lógica especial da ficção" deve ser criada se pretendemos saber como avaliar raciocinios concernentes à ficção. De acordo com a teoria proposta acima, no entanto, nenhum expediente drástico como esse é forçado sobre nós. Precisamos apenas apontar que: (1) Lady Macbeth tem a propriedade de ter nenhuma criança, uma vez que ela é uma entidade teórica da crítica e, dessa forma, não é o tipo de coisa que poderia ter crianças, e (2) ela não sustenta essa propriedade. nem sua negação (a propriedade de ter uma ou mais crianças). A Lei do Terceiro Excluído requer que, para cada propriedade, um objeto tenha ou aquela propriedade ou sua negação. Mas nem essa lei, nem qualquer outro principio da lógica diz algo sobre quais são as propriedades que um objeto deve sustentar. (Um objeto ficcional pode sustentar um conjunto logicamente inconsistente de propriedades. Barsetshire, por exemplo, sustenta um conjunto inconsistente de propriedades

\footnotetext{
7 Para um desenvolvimento mais completo de vários aspectos da teoria esboçada aqui, veja meu artigo "Creatures of Fiction" (INWAGEN, Peter van. Creatures of Fiction. American Philosophical Quarterly, Illinois, v. 14, p. 299-308, 1977.
} 
geográficas: esse é o porquê de não se poder desenhar um mapa coerente desse condado). Portanto, não há a necessidade de uma lógica especial da ficção. Uma vez que este artigo foi uma aplicação das ideias de Quine sobre ontologia para um tópico especial, a ontologia da ficção, este é um ponto apropriado no qual podemos encerrá-lo. Pois agora retribuimos parcialmente a Quine por seu serviço à ontologia da ficção, mostrando como preocupações sobre a necessidade de uma lógica especial da ficção podem ser evitadas; e não realizamos um desserviço à filosofia da lógica de Quine, uma vez que um de seus principios centrais é que nenhum assunto requer uma lógica especial para si.

\section{Agradecimentos}

Gostaria de agradecer ao Prof. Peter van Inwagen pela atenção desdobrada durante o processo de tradução deste artigo, à Hannah Wampler da John Hopkins University Press pela gentil concessão dos direitos autorais para a publicação deste material, e também aos pareceristas anônimos, aos editores da Revista Veritas e aos revisores da Poá Comunicação pelas importantes sugestões de melhorias do texto.

\section{Italo Lins Lemos}

Doutor em Filosofia pela Universidade Federal de Santa Catarina (UFSC), em Florianópolis, SC, Brasil. Professor Temporário do Departamento de Filosofia da Universidade Estadual de Maringá (UEM), em Maringá, $\mathrm{PR}$, Brasil.

\section{Endereço para correspondência}

\section{Italo Lins Lemos}

Universidade Estadual de Maringá

Centro de Ciências Humanas, Letras e Artes

Departamento de Filosofia

Zona 7. 87020900

Maringá, PR, Brasil antes da publicação. 